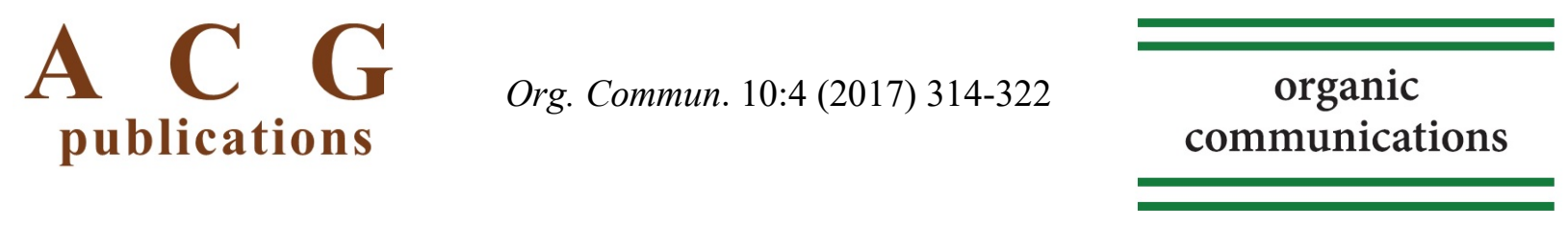

\title{
Synthesis of novel impurities in 2-(2-(4-fluorophenyl)-2-oxo-1- phenylethyl)-4-methyl-3-oxo-N-phenylpentanamide; an atorvastatin intermediate
}

\author{
A. Appala Naidu ${ }^{\bullet}$ and G. Veera Raghava Sharma*๑ \\ Department of Chemistry, Institute of Technology, GITAM (deemed to be University under UGC act \\ 1956) Rushikonda, Visakhapatnam 530045, AP, India
}

(Received April 06, 2017; Revised November 15, 2017; Accepted November 18, 2017)

\begin{abstract}
R,5R)-7-(3-(phenylcarbamoyl)-5-(4-fluorophenyl)-2-isopropyl-4-phenyl-1H-pyrrol-1-yl)-3,5-dihydroxyheptanoic acid, calcium salt (2:1)trihydrate (1), a 3-hydroxy-3-methylglutaryl coenzyme A reductase inhibitor, was demonstrated to be effective in reducing both triglyceride and cholesterol. In present communication, two novel impurities i.e.,2-acetyl-4-(4-fluorophenyl)-4-oxo-N,3-diphenylbutanamide (18) and 2-(2-(3-fluoro phenyl)-2-oxo-1phenylethyl)-4-methyl-3-oxo-N-phenylpentanamide (19)of 2-(2-(4-fluorophenyl)-2-oxo-1-phenylethyl)-4-methyl-3-oxo$\mathrm{N}$-phenylpentanamide (2),were reported along with their identification and isolation. The compounds were characterized by spectral techniques such as IR, 1HNMR, 13C NMR and mass.
\end{abstract}

Keywords: Atorvastatin; key intermediate; novel impurity synthesis. C 2017 ACG Publications. All rights reserved.

\section{Introduction}

$(3 R, 5 R)-7-(3-($ phenylcarbamoyl)-5-(4-fluorophenyl)-2-isopropyl-4-phenyl-1H-pyrrol-1-yl)-3,5dihydroxy heptanoic acid, calcium salt (2:1)trihydrate (1) is a 3-hydroxy-3-methylglutaryl coenzyme A reductase inhibitor,which has been demonstrated to be effective in reducing both triglyceride and cholesterol ${ }^{1}$. Almost all manufacturers of this drug use 2-(2-(4-fluorophenyl)-2-oxo-1-phenylethyl)-4-methyl-3-oxo- $N$ phenylpentanamide (2) as a key intermediate ${ }^{2,3}$ (Figure 1).

Even negligible quantity of impurities ${ }^{2-7}$ may have impact on the quality of bulk drug process. Thus, high standard principles and good manufacturing practices are required for reducing impurity level. Presence of impurity, even in small quantity, may influence the efficiency and safety of the pharmaceutical products.

*Corresponding author: E-mail: sharmagvr@yahoo.co.uk; gvrs276@gmail.comPhone: 00919642575394

The article was published by ACG Publications

www.acgpubs.org/OC/index.htm (C) October-December 2017 EISSN:1307-6175

DOI: http://doi.org/10.25135/acg.oc.31.17.04.015 


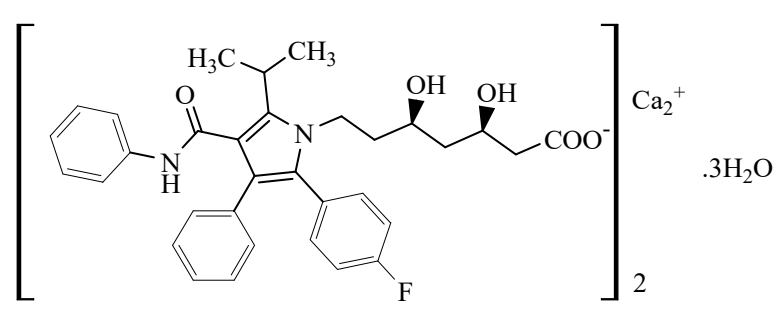

1<smiles>CC(C)C(=O)C(C(=O)Nc1ccccc1)C(C(=O)c1ccc(F)cc1)c1ccccc1</smiles>

2

Figure 1. Structures of atorvastatin calcium and its key intermediate

During the manufacturing of 2-(2-(4-fluorophenyl)-2-oxo-1-phenylethyl)-4-methyl-3-oxo- $N$ phenylpentanamide, Raju et. al., reported number of impurities namely 4-methyl-3-oxo-2-(2-oxo-1,2diphenylethyl)- $N$-phenylpentanamide, a desfluoro impurity (3), 2-(2-(3,4-difluorophenyl)-2-oxo-1phenylethyl)-4-methyl-3-oxo- $N$-phenylpentanamide, a difluoro analog (4), 1,4-bis(4-fluorophenyl)-2,3diphenylbutane-1,4-dione (5) and methyl 2-(2-(4-fluorophenyl)-2-oxo-1-phenylethyl)-4-methyl-3oxopentanoate $(6)^{2}$ (Figure 2). Pai et. al., reported novel impurities of (E)-2-(2-(4-fluorophenyl)-2-oxo-1phenylethyl)-3-hydroxy-4-methyl- $N$-phenylpent-2-enamide, a keto enol form (7)and (Z)-2-(2-(4fluorophenyl)-2-oxo-1-phenylethoxy)-3-hydroxy-4-methyl- $N$-phenylpent-2-enamide, an O-alkylated impurity $(\mathbf{8})^{3}$<smiles>CC(C)C(=O)C(C(=O)Nc1ccccc1)C(C(=O)c1ccccc1)c1ccccc1</smiles>

3<smiles>CC(C)C(=O)C(C(=O)Nc1ccccc1)C(C(=O)c1ccc(F)c(F)c1)c1ccccc1</smiles>

4<smiles>CC(C)C(O)=C(C(=O)Nc1ccccc1)C(C(=O)c1ccc(F)cc1)c1ccccc1</smiles>

7<smiles>O=C(c1ccc(F)cc1)C(c1ccccc1)C(C(=O)c1ccc(F)cc1)c1ccccc1</smiles>

5<smiles>COC(=O)C(C(=O)C(C)C)C(C(=O)c1ccc(F)cc1)c1ccccc1</smiles>

6<smiles>CC(C)/C(O)=C(\OC(C(=O)Nc1ccccc1)c1ccccc1)C(=O)c1ccc(F)cc1</smiles>

8

Figure 2. Structures of some earlier isolated impurities

In this present communication, we report identification, isolation and synthesis of some novel impurities, which are formed during the manufacturing of 2-(2-(4-fluorophenyl)-2-oxo-1-phenylethyl)-4methyl-3-oxo- $N$-phenylpentanamide. They were characterized by spectroscopic techniques. 
Impurities in 2-(2-(4-fluorophenyl)-2-oxo-1-phenylethyl)-4-methyl-3-oxo-N-phenylpentanamide

316

\section{Experimental}

\subsection{General}

All chemical reagents and solvents were procured from Acros, Fisher scientific Acros and Sigma-Aldrich etc., which are used without further purification. All the reactions were conducted under inert conditions. The products were purified appying column chromatography, crystalization and precipitation techniques. Silicagel (100-200 mesh) was used as a solid phase for column chromatography. Precoated silica aluminium sheets were used for TLC. The products were identified on TLC plate by using iodine or UV cabinet. NMR spectra were recorded on Bruker $400 \mathrm{MHz}$ by using $\mathrm{CDCl}_{3}$ and DMSO- $\mathrm{d}_{6}$ as solvents. Mass analyses were recorded on Apex. IR ( $\mathrm{KBr}$ disc) spectra were obtained on Bruker.

2.2. Synthesis of 3-oxo- $N$-phenylbutanamide (22):A mixture of methyl acetoacetate (20) $(10 \mathrm{~g}, 86.21 \mathrm{mmol})$, aniline $(15)(8.41 \mathrm{~g}, 90.3 \mathrm{mmol})$ and triethylamine $(1.85 \mathrm{~g}, 18.3 \mathrm{mmol})$ was stirred at $80-85^{\circ} \mathrm{C}$ for $1 \mathrm{~h}$. Then the temperature was gradually raised to $120-125^{\circ} \mathrm{C}$ and stirred for $6-8 \mathrm{~h}$, during which the liberated methanol was collected through distillation. The absence of starting material was monitored by TLC, using hexane/EtOAc mixtureas a mobile phase (8:2). After completion of the reaction, it was cooled cool to room temperature. The reaction mixture was quenched with $2 \mathrm{~N} \mathrm{HCl}$ solution $(20 \mathrm{~mL})$ and extracted with $\mathrm{CH}_{2} \mathrm{Cl}_{2}(30$ $\mathrm{mL})$. The organic layer was sequentially wash with $1 \mathrm{~N} \mathrm{HCl}(5 \mathrm{~mL}), 5 \% \mathrm{NaHCO}_{3}(5 \mathrm{~mL})$ and $5 \% \mathrm{NaCl}(5$ $\mathrm{mL})$. The organic layer was concentrated under reduced pressure to give a brown product. $(12.5 \mathrm{~g}, 81.9 \%$ yield). ${ }^{1} \mathrm{H}-\mathrm{NMR}\left(400 \mathrm{MHz}, \mathrm{CDCl}_{3}\right): \delta 9.17(\mathrm{~s}, 1 \mathrm{H}), 7.54(\mathrm{~d}, J=8 \mathrm{~Hz}, 2 \mathrm{H}), 7.33(\mathrm{t}, J=8 \mathrm{~Hz}, 2 \mathrm{H}), 7.12$ (t, $J=8$ $\mathrm{Hz}, 1 \mathrm{H}), 3.56(\mathrm{~s}, 2 \mathrm{H}), 2.30(\mathrm{~s}, 3 \mathrm{H}) .{ }^{13} \mathrm{C}$ NMR $\left(400 \mathrm{MHz}, \mathrm{CDCl}_{3}\right): \delta 209.32,164.74,137.39,128.35,128.29$, 123.95, 119.80, 51.69, 33.39. MS (EI): $m / z: 178$. Anal Calcd. for $\mathrm{C}_{10} \mathrm{H}_{11} \mathrm{NO}_{2}: \mathrm{C}, 67.78 ; \mathrm{H}, 6.26 ; \mathrm{N}$, 7.90.Found: C, 67.05; H, 6.39; N, 7.68.

2.3. Synthesis of 2-acetyl-4-(4-fluorophenyl)-4-oxo-N,3-diphenylbutanamide (18):A mixture of 2-chloro-1-(4fluorophenyl)-2-phenylethanone (23) $\quad(10 \mathrm{~g}, \quad 40.2 \mathrm{mmol}), \quad \mathrm{K}_{2} \mathrm{CO}_{3} \quad(8 \mathrm{~g}, \quad 57.8 \mathrm{mmol})$ and 3-oxo- $N$ phenylbutanamide (22) $(9.5 \mathrm{~g}, 46.3 \mathrm{mmol})$ was refluxed in acetone $(40 \mathrm{~mL})$ for $8-10 \mathrm{~h}$. The absence of starting material was monitored by TLC using hexane/EtOAc mixture as a mobile phase (8:2). Cool to 25$35^{\circ} \mathrm{C}$. The mixture was cooled to room temperature, filtered and washed with acetone $(20 \mathrm{~mL})$. The solvent of the filtrate was removed under reduced pressure to obtain a crude solid product, to which isopropyl alcohol was added and the mixture was refluxed for $1 \mathrm{~h}$. Then, the mixture was cooled to room temperature and the solid product was separated by filtration and washed with isopropyl alcohol $(10 \mathrm{~mL})$. It was dried at $70-80^{\circ} \mathrm{C}$ to obtain a white solid material which required no further purification $\left(11.5 \mathrm{~g}, 68.4 \%\right.$ yield).m.p. $174-176^{\circ} \mathrm{C}$. ${ }^{1} \mathrm{H}-\mathrm{NMR}\left(400 \mathrm{MHz}, \mathrm{CDCl}_{3}\right): \delta 8.02-7.98(\mathrm{~m}, 2 \mathrm{H}), 7.58(\mathrm{~s}, 1 \mathrm{H}), 7.33(\mathrm{~d}, J=8 \mathrm{~Hz}, 2 \mathrm{H}), 7.26-7.21(\mathrm{~m}, 5 \mathrm{H}), 7.16$ $(\mathrm{d}, J=8 \mathrm{~Hz}, 2 \mathrm{H}), 7.10-7.01(\mathrm{~m}, 3 \mathrm{H}), 5.41(\mathrm{~d}, J=7 \mathrm{~Hz}, 1 \mathrm{H}), 4.52(\mathrm{~d}, J=7 \mathrm{~Hz}, 1 \mathrm{H}), 2.36(\mathrm{~s}, 3 \mathrm{H}) .{ }^{13} \mathrm{C}$ NMR $(400$ MHz, DMSO-d $\mathrm{d}_{6}$ : $\delta 202.00,196.54,166.24,163.73,138.13,135.16,132.25,132.23,131.71,131.61,128.81$, 128.67, 127.52, 123.93, 119.69, 115.90, 115.68, 65.05, 51.71, 28.58.IR (KBr, cm $\left.{ }^{-1}\right): 3151,2955,1705,1650$, 1612, 1442, 1164, 850. MS (EI): $m / z: 390.2$. Anal Calcd. forC ${ }_{24} \mathrm{H}_{20} \mathrm{FNO}_{3}: \mathrm{C}, 74.02 ; \mathrm{H}, 5.18 ; \mathrm{N}, 3.60$. Found: C, 74.35; H, 5.10; N, 3.65 .

2.4.Synthesis of 1-(3-fluorophenyl)-2-phenylethanone (28): To a mixture of Deionised Mineral(DM) water $(200 \mathrm{~mL})$, cadmium chloride monohydrate $(8.55 \mathrm{~g}, 42.46 \mathrm{mmol})$, indium chloride $(0.89 \mathrm{~g}, 4.02 \mathrm{mmol})$, benzyl chloride (26) (10.3g, $80.1 \mathrm{mmol})$ and zinc dust $(5.25 \mathrm{~g}, 80.3 \mathrm{mmol})$ was added 3-fluoro benzaldehyde $(\mathbf{2 5})(5 \mathrm{~g}$, $40.3 \mathrm{mmol}$ ), and the mixture was stirred at room temperature for $8-10 \mathrm{~h}$. Absence of starting material was monitored by TLC, using a mixture of hexane/EtOAcas a mobile phase $(8: 2)$. EtOAc $(20 \mathrm{~mL})$ was added to the reaction mixture, stirred for $15 \mathrm{~min}$, filtered and washed, with EtOAc $(20 \mathrm{~mL})$. The filtrate was washed sequentially with $5 \% \mathrm{NaHCO}_{3}(2 \times 20 \mathrm{~mL})$ and $5 \% \mathrm{Na}_{2} \mathrm{SO}_{3}(3 \times 20 \mathrm{~mL})$.The organic layer was concentrated under reduced pressure to give a yellow crude product. It was purified by column chromatography using silica gel (100-200 mesh) as a stationary phase, and the mixture of hexane/EtOAc as a mobile phase to obtain pure 
1-(3-fluorophenyl)-2-phenylethanol (27)(5.5g). It was dissolved in $25 \mathrm{~mL}$ of acetone and slowly added to Jones reagent (Preparation: to $2.5 \mathrm{~g}$ of $\mathrm{CrO}_{3}$ was added $2.5 \mathrm{~mL}$ of $\mathrm{H}_{2} \mathrm{SO}_{4}$ to observe a clear solution. It was slowly added into $\mathrm{DM}$ water $7.5 \mathrm{~mL}$ ) at room temperature. Absence of starting material was monitored by TLC using a mixture of hexane/EtOAc as a mobile phase (8:2). The mixture was slowly added into DM water $(55 \mathrm{~mL})$ and extracted with $\mathrm{CH}_{2} \mathrm{Cl}_{2}(55 \mathrm{~mL})$. The organic layer was-concentrated under reduced pressure to give a crude product, which was dissolved in n-hexane $(50 \mathrm{~mL})$ and sequentially washed with $5 \% \mathrm{NaHCO}_{3}$ $(2 \times 20 \mathrm{~mL}), 5 \% \mathrm{NaHSO}_{3}(3 \times 20 \mathrm{~mL})$ and $\mathrm{DM}$ water $(20 \mathrm{~mL})$. The organic layer was concentrated under reduced pressure to give a yellow semi solid $(3.7 \mathrm{~g}, 42.9 \%$ yield $) .{ }^{1} \mathrm{H}-\left(400 \mathrm{MHz}, \mathrm{CDCl}_{3}\right): \delta 7.80(\mathrm{~d}, J=8 \mathrm{~Hz}$, $1 \mathrm{H}), 7.70(\mathrm{~d}, J=8 \mathrm{~Hz}, 1 \mathrm{H}), 7.48-7.40(\mathrm{~m}, 2 \mathrm{H}), 7.34-7.28(\mathrm{~m}, 2 \mathrm{H}), 7.27-7.25(\mathrm{~m}, 3 \mathrm{H}), 4.27(\mathrm{~s}, 2 \mathrm{H}) .{ }^{13} \mathrm{C}$ NMR (400 MHz, $\mathrm{CDCl}_{3}$ ): $\delta$ 195.66, 164.13, 134.19, 132.75, 132.72, 131.02, 130.92, 129.19, 128.42, 126.68, 119.50 , 115.29,45.08. MS (EI): m/z: 213.4. Anal Calcd. for $\mathrm{C}_{14} \mathrm{H}_{11}$ FO: C, 78.49; H, 5.18.Found: C, 77.95; H, 5.30.

2.5. Synthesis of 2-bromo-1-(3-fluorophenyl)-2-phenylethanone (29): To a mixture of 1-(3-fluorophenyl)-2phenylethanone $(\mathbf{2 8})(3.7 \mathrm{~g}, 17.27 \mathrm{mmol})$ and $\mathrm{CH}_{2} \mathrm{Cl}_{2}(37 \mathrm{~mL})$ was added $0.12 \mathrm{~mL}$ of $30 \% \mathrm{HBr}$ in $\mathrm{AcOH}$ and then a cold solution of $\mathrm{Br}_{2}(3.7 \mathrm{~g}, 23.12 \mathrm{mmol})$ in $7.5 \mathrm{~mL}$ of $\mathrm{CH}_{2} \mathrm{Cl}_{2}$. The reaction progress was monitored by TLC using a mixture of hexane $/ \mathrm{CH}_{2} \mathrm{Cl}_{2}$ as a mobile phase (1:1). After completion of the reaction, the organic layer was sequentially washed with $5 \% \mathrm{Na}_{2} \mathrm{SO}_{3}(3 \times 10 \mathrm{~mL}), 5 \% \mathrm{NaHCO}_{3}(10 \mathrm{~mL})$ and $5 \% \mathrm{NaCl}(10 \mathrm{~mL})$. It was concentrated under reduced pressure to give a brown semi solid $\left(5 \mathrm{~g}, 98.8 \%\right.$ yield). ${ }^{1} \mathrm{H}-\mathrm{NMR}$ (400 MHz, $\left.\mathrm{CDCl}_{3}\right): \delta 7.76(\mathrm{~d}, J=8 \mathrm{~Hz}, 1 \mathrm{H}), 7.66(\mathrm{~d}, J=8 \mathrm{~Hz}, 1 \mathrm{H}), 7.53-7.50(\mathrm{~m}, 2 \mathrm{H}), 7.40-7.29(\mathrm{~m}, 4 \mathrm{H}), 7.29(\mathrm{t}, J=8 \mathrm{~Hz}$, $1 \mathrm{H}), 6.31(\mathrm{~s}, 1 \mathrm{H}) .{ }^{13} \mathrm{C}$ NMR $\left(400 \mathrm{MHz}, \mathrm{CDCl}_{3}\right): \delta 189.70,164.17,135.44,133.69,131.60,131.50,130.27$, 130.24, 129.67, 128.88, 128.80, 120.65, 115.67, 61.89. MS (EI): $m / z: 292$. Anal Calcd. for $\mathrm{C}_{14} \mathrm{H}_{10} \mathrm{BrFO}: \mathrm{C}$, 57.36; H, 3.44.Found: C, 57.33; H, 3.65.

2.6. Synthesis of 2-(2-(3-fluorophenyl)-2-oxo-1-phenylethyl)-4-methyl-3-oxo-N-phenyl pentanamide (19): To the mixture of $\mathrm{K}_{2} \mathrm{CO}_{3}(3.5 \mathrm{~g}, 25.34 \mathrm{mmol})$ and 4-methyl-3-oxo- $N$-phenylpentanamide (16) $(4.4 \mathrm{~g}, 21.32 \mathrm{mmol})$ in acetone $(15 \mathrm{~mL})$ was added 2-bromo-1-(3-fluorophenyl)-2-phenylethanone (29) $(5 \mathrm{~g}, 17.05 \mathrm{mmol})$ in $5.5 \mathrm{~mL}$ of acetone. The mixture was stirred at room temperature for $6-8 \mathrm{~h}$. Absence of the starting material was monitored by TLC using hexane/EtOAc as a mobile phase (8:2). After completion of the reaction, it was filtered and washed with acetone $(10 \mathrm{~mL})$. The filtrate was concentrated under reduced pressure. To the remaining residue was added $20 \mathrm{~mL}$ isopropyl alcohol and the solution was refluxed for $1 \mathrm{~h}$, after which the product was collected by filtration and wash with isopropyl alcohol $(5 \mathrm{~mL})$. The material was dried at $70-80^{\circ} \mathrm{C}$ to obtain a white solid. (4g, 56\% yield).m.p. $207-209^{\circ} \mathrm{C} .{ }^{1} \mathrm{H}-\mathrm{NMR}\left(400 \mathrm{MHz}, \mathrm{CDCl}_{3}\right): \delta 7.75(\mathrm{~s}, 1 \mathrm{H}), 7.64-7.61$ (m, 1H), 7.36-7.33 (m, 2H), 7.32-7.21 (m, 5H), 7.19-7.17 (m, 3H), 7.15-7.08 (m, 3H), $5.37(\mathrm{~d}, J=7 \mathrm{~Hz}, 1 \mathrm{H})$, $4.57(\mathrm{~d}, J=7 \mathrm{~Hz}, 1 \mathrm{H}), 3.01-2.94(\mathrm{~m}, 1 \mathrm{H}), 1.24(\mathrm{~d}, J=7 \mathrm{~Hz}, 3 \mathrm{H}), 1.16(\mathrm{~d}, J=7 \mathrm{~Hz}, 3 \mathrm{H}) .{ }^{13} \mathrm{C}$ NMR $(400 \mathrm{MHz}$, DMSO-d $\left.{ }_{6}\right): \delta 208.01,196.84,164.89,160.96,138.06,137.85,137.79,134.78,131.02,130.94,128.89,128.69$, $128.60,127.59,124.96,124.93,123.94,120.33,120.12,119.73,114.99,63.02,51.98,38.86,18.79,17.88$. IR $\left(\mathrm{KBr}, \mathrm{cm}^{-1}\right): 3241,2978,1650,1595,1438,1155,692,793 . \mathrm{MS}(\mathrm{EI}): \mathrm{m} / z: 418.1$.Anal Calcd. for $\mathrm{C}_{26} \mathrm{H}_{24} \mathrm{FNO}_{3}$ : C, 74.80; H, 5.79; N, 3.36.Found: C, 74.55; H, 5.35; N, 3.69.

\section{Results and Discussion}

It is known that 2-(2-(4-fluorophenyl)-2-oxo-1-phenylethyl)-4-methyl-3-oxo- $N$-phenylpentan-amide (2)is a key intermediate of Atorvastatin calcium (1) used for treatment of dyslipidemia and prevention of cardiovascular disease.

2-(2-(4-fluorophenyl)-2-oxo-1-phenylethyl)-4-methyl-3-oxo- $N$-phenylpentanamide (2) was prepared from phenylacetic acid (9), fluorobenzene (11) and methyl isobutyrylacetate (14). This intermediate was further reacted with tert-butyl 2-((4R,6R)-6-(2-aminoethyl)-2,2-dimethyl-1,3-dioxan-4-yl)acetate (17) to give $(3 R, 5 R)-7-(3-($ phenylcarbamoyl)-5-(4-fluorophenyl)-2-isopropyl-4-phenyl-1H-pyrrol-1-yl)-3,5-dihydroxy heptanoic acid, calcium salt (2:1)trihydrate (Atorvastatin calcium) (1)(Scheme 1). 


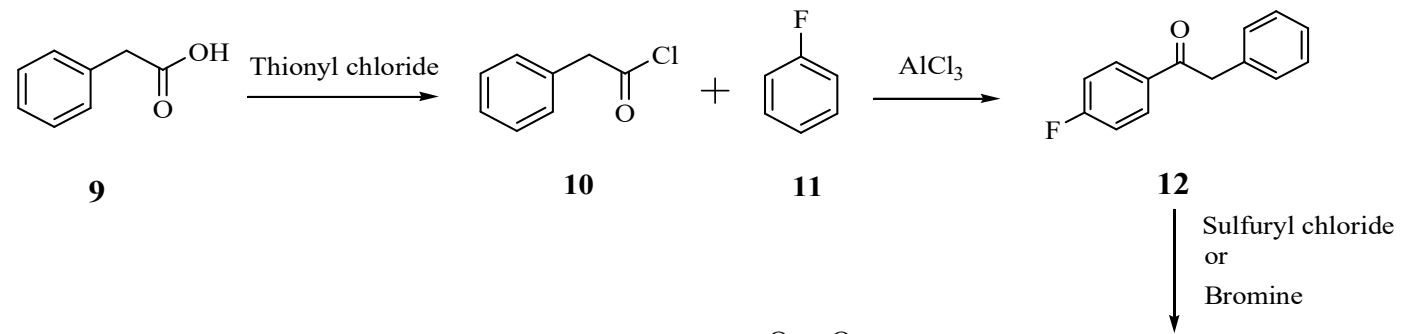<smiles>COC(=O)CC(=O)C(C)C</smiles>

14<smiles>CC(C)C(=O)CC(=O)Nc1ccccc1</smiles>

16<smiles>[X]C(C(=O)c1ccc(F)cc1)c1ccccc1</smiles>

13<smiles>CC(C)(C)OC(=O)C[C@H]1C[C@H](CCN)OC(C)(C)O1</smiles>

17

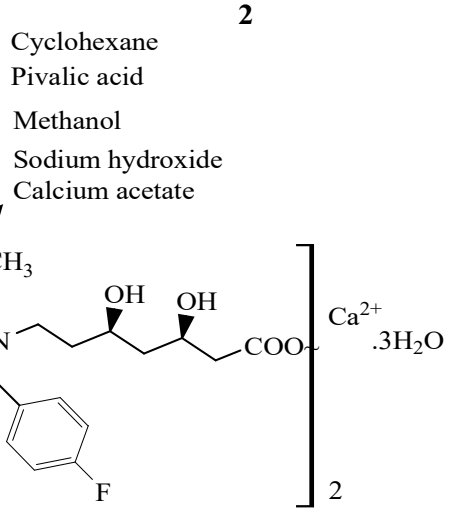

1

Scheme1. Synthesis of (3R,5R)-7-(3-(phenylcarbamoyl)-5-(4-fluorophenyl)-2-isopropyl-4-phenyl-1H-pyrrol1-yl)-3,5-dihydroxy heptanoic acid, calcium salt (2:1)trihydrate (Atorvastatin calcium)

In this study, the possible impurities i.e.,2-acetyl-4-(4-fluorophenyl)-4-oxo- $N, 3$-diphenylbutanamide (18) and 2-(2-(3-fluorophenyl)-2-oxo-1-phenylethyl)-4-methyl-3-oxo- $N$-phenylpentanamide (19), formed during the synthesis of 2-(2-(4-fluorophenyl)-2-oxo-1-phenylethyl)-4-methyl-3-oxo- $N$-phenylpentanamide (2), were synthesized (Scheme 1 and Figure 3). 


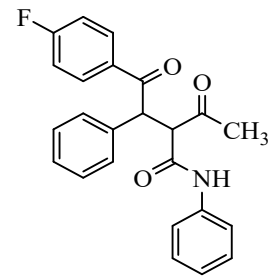

18

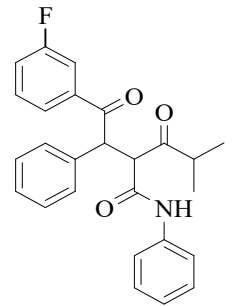

19

Figure3. Structures of novel impurities

It is a general method that methyl isobutyrylacetate(14) is synthesized by the reaction of methyl acetoacetate (20) with isobutyryl chloride (21) in the presence of calcium hydroxide and ammonium chloride(Scheme 2).<smiles>COC(=O)CC(C)=O</smiles>

20

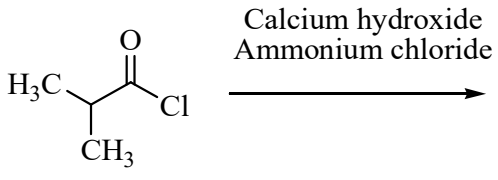

21<smiles>COC(=O)CC(=O)C(C)C</smiles>

14

Scheme 2. Synthesis of methyl isobutyrylacetate

Unreacted methyl acetoacetate (20) in methyl isobutyrylacetate (14) was reacted with aniline (15) in the presence of trimethylamine to give 3-oxo- $N$-phenylbutanamide (22). Condensation of 22 with 2-chloro-1(4-fluorophenyl)-2-phenylethanone (23) in presence of potassium carbonate in acetone produced 2-acetyl-4(4-fluorophenyl)-4-oxo- $N, 3$-diphenylbutanamide (18)(Scheme 3).<smiles>COC(=O)CC(C)=O</smiles>

Scheme 3. Synthesis of 2-acetyl-4-(4-fluorophenyl)-4-oxo- N,3-diphenylbutanamide

2-Acetyl-4-(4-fluorophenyl)-4-oxo- $N, 3$-diphenylbutanamide (18), formed due to the presence of methyl acetoacetate (20), was further reacted with tert-butyl 2-((4R,6R)-6-(2-aminoethyl)-2,2-dimethyl-1,3dioxan-4-yl)acetate (17)to yield (3R,5R)-7-(3-(phenylcarbamoyl)-5-(4-fluorophenyl)-2-methyl-4-phenyl-1Hpyrrol-1-yl)-3,5-dihydroxyheptanoic acid, calcium salt (2:1)trihydrate(a methyl analog of atorvastatin calcium) (24)(Scheme 4). 
<smiles>CC(C)(C)OC(=O)C[C@H]1C[C@H](CCN)OC(C)(C)O1</smiles>

17

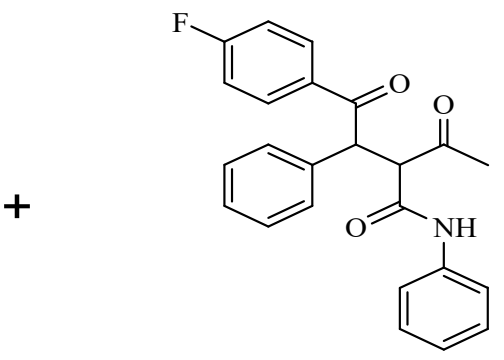

18

$$
\mid \begin{aligned}
& \text { Cyclohexane } \\
& \text { Pivalic acid } \\
& \text { Methanol } \\
& \text { Sodium hydroxide } \\
& \text { Calcium acetate }
\end{aligned}
$$

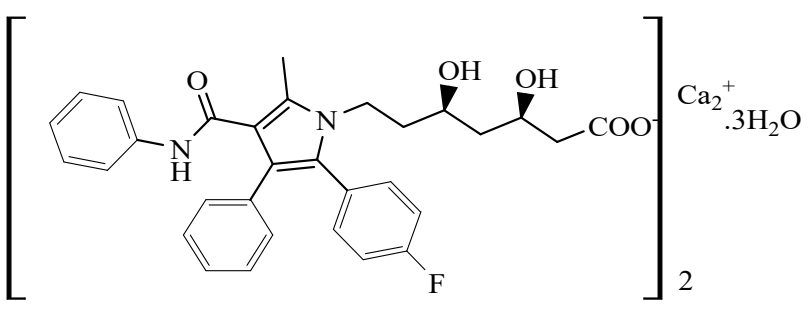

24

Scheme 4. Synthesis of (3R,5R)-7-(3-(phenylcarbamoyl)-5-(4-fluorophenyl)-2-methyl-4-phenyl-1H-pyrrol-1yl)-3,5-dihydroxyheptanoic acid, calcium salt (2:1)trihydrate (methyl analog of atorvastatin calcium)

2-(2-(3-Fluorophenyl)-2-oxo-1-phenylethyl)-4-methyl-3-oxo- $N$-phenylpentanamide (19),which was synthesized similarly, may form due to the reaction temperature during Friedel crafts acetylation of phenyl acetyl chloride with fluoro benzene in the presence of aluminum chloride. Formation of this impurity is very low, (less than $0.05 \%$ ), hence, it is difficult to isolate through column chromatography. Thus, it was prepared by reacting a mixture of cadmium chloride monohydrate, indium chloride, benzyl chloride (26) and zinc dust with 3-fluoro benzaldehyde (25) in water at room temperature to give 1-(3-fluorophenyl)-2-phenylethanol (27). It was undergone oxidation in the presence of Jones reagent in acetone to obtain-1-(3-fluorophenyl)-2phenylethanone (28), which, upon bromination, yielded 2-bromo-1-(3-fluorophenyl)-2-phenylethanone (29). It was further reacted with 4-methyl-3-oxo- $N$-phenylpentanamide (16) in the presence of potassium carbonate in acetone to gives 2-(2-(3-fluorophenyl)-2-oxo-1-phenylethyl)-4-methyl-3-oxo- $N$-phenylpentanamide (19)(Scheme 5). 
<smiles>O=Cc1cccc(F)c1</smiles>

25<smiles>ClCc1ccccc1</smiles>

26<smiles>OC(Cc1ccccc1)c1cccc(F)c1</smiles>

27<smiles>O=C(Cc1ccccc1)c1cccc(F)c1</smiles>

28<smiles>CC(C)C(=O)CC(=O)Nc1ccccc1</smiles>

16
Bromine $\mathrm{HBr}$ In $\mathrm{AcOH}$<smiles>O=C(c1cccc(F)c1)C(Br)c1ccccc1</smiles>

29

Scheme 5. Synthesis of 2-(2-(3-fluorophenyl)-2-oxo-1-phenylethyl)-4-methyl-3-oxo- $N$ phenylpentanamide

2-(2-(3-Fluorophenyl)-2-oxo-1-phenylethyl)-4-methyl-3-oxo- $N$-phenylpentanamide (19) was reacted with tert-butyl 2-((4R,6R)-6-(2-aminoethyl)-2,2-dimethyl-1,3-dioxan-4-yl) acetate (17) to obtain $(3 R, 5 R)$-7-(3(phenylcarbamoyl)-5-(3-fluorophenyl)-2-isopropyl-4-phenyl-1H-pyrrol-1-yl)-3,5-dihydroxy heptanoic acid, calcium salt (2:1)trihydrate (a 3-fluoro analog of atorvastatin calcium) (30)(Scheme 6).<smiles>CC(C)(C)OC(=O)C[C@H]1C[C@H](CCN)OC(C)(C)O1</smiles>

17

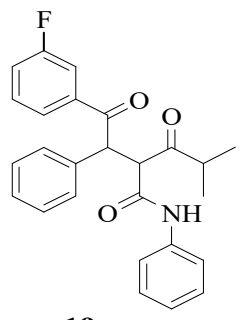

19

Cyclohexane Pivalic acid Methanol

Sodium hydroxide Calcium acetate

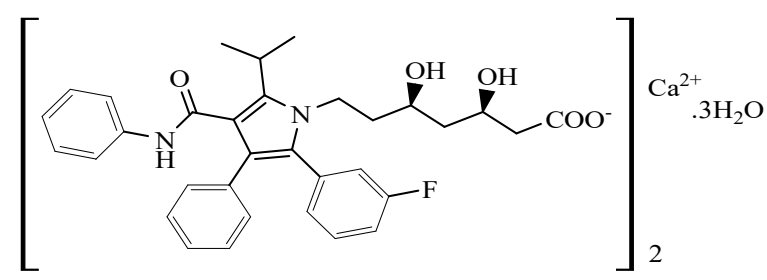

30

Scheme 6. Synthesis of (3R,5R)-7-(3-(phenylcarbamoyl)-5-(3-fluorophenyl)-2-isopropyl-4-phenyl-1H-pyrrol-

1-yl)-3,5-dihydroxy heptanoic acid, calcium salt (2:1)trihydrate

(3-fluoro analog of atorvastatin calcium) 


\section{Conclusion}

To summarize, we have identified and synthesized novel impurities i.e., 2-acetyl-4-(4-fluorophenyl)-4oxo- $N, 3$-diphenylbutanamide (18) and 2-(2-(3-fluorophenyl)-2-oxo-1-phenylethyl)-4-methyl-3-oxo- $N$ phenylpentanamide (19), which form during manufacturing of 2-(2-(4-fluorophenyl)-2-oxo-1-phenylethyl)-4methyl-3-oxo- $N$-phenylpentanamide (2). Those impurities are well characterized by spectroscopic techniques. We will further study the impact of these impurities on Atorvastatin calcium (1).

\section{Acknowledgements}

We thank Laila-Impex, Vijayawada and Institute of Life Sciences, University of Hyderabad, Hyderabad for the spectral data. This work is part of Ph.D. thesis of A. Appala Naidu. A. Appala Naidu is grateful to Vijayasree Organics for the encouragement. We acknowledge the financial support of DST-FIST to Department of Chemistry, Institute of Science and Institute of Technology, GITAM(deemed to be University under UGC act 1956) and TEQIP to Institute of Technology, GITAM.

\section{ORCID}

A. Appala Naidu: 0000-0003-4265-6756

G. Veera Raghava Sharma: 0000-0002-2649-1923

\section{References}

[1] Rebecca, G.; Bakker-Arkema, M.S.; Michael, H.; Davidson, M.D.; Robert, J.; Goldstein, M.D.; Jean Davignon, M.D.; Jonathan, L.; Isaacsohn, M.D.; Stuart, R.; Weiss, M.D.; Leonard, M; Keilson, MD.; W. Virgil Brown, M.D.; Valery, T.; Miller, M.D.; Linda, J.; Shurzinske, MS.; Donald, M.; Black, M.D. Efficacy and Safety of a New HMG-CoA Reductase Inhibitor, Atorvastatin, in Patients With Hypertriglyceridemia. JAMA. 1996, 275(2), 128133

[2] Pai, G.G.; Kishore, N.; Chaudhari, N.P.; Anjaneyulu, N.; Ghogare, B.N. 2011, U.S. Patent No. 7,872,154 B2.

[3] Islam M.; Sarkar, M.S. Detection of impurities in a tablet of Atorvastatin, KYAMCH J. 2011, 1(2), 43-47.

[4] Sagyam, R.; Himabindhu, V.; Reddy, P.P.; Reddy, M.G. An efficient synthesis of highly substituted pyrrole and bis pyrrole derivatives. J. Het. Chem., 2007, 44, 923-926

[5] Eranki, R.J.V.; Inki, G.; Jayaramn, V.; Vidiyala, S.R.; Ramulu, J.S. New stability indicating method for qualification of impurities in Amlodipine and Atorvastatin calcium tablet by validated HPLC. Int. J. Pharmaceut. Res. Scholar., 2013, 2(4), 458-471

[6] De Lange, B. 2013, U.S. Patent No. 20130041162 A.

[7] Roy J. Pharmaceutical impurities: A mini-review.AAPS PharmSciTech. 2002, 3, 1-8.

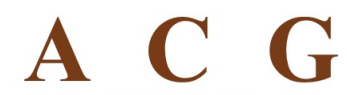

publications

(C) 2017 ACG Publications 